\title{
CORPUS Corpus
}

Archivos virtuales de la alteridad americana

Vol. 10, No. $2 \mid 2020$

Julio / Diciembre 2020

\section{Materialidad, creatividad cultural y práctica social: una etnografía de las cosas del pasado entre los habitantes de San Antonio del Cajón (Catamarca, Argentina}

Materiality, cultural creativity and social practices: ethnography of things from the past among the inhabitants in San Antonio del Cajón (Catamarca, Argentina)

Bárbara Betsabé Martínez

\section{OpenEdition}

\section{Journals}

Electronic version

URL: http://journals.openedition.org/corpusarchivos/3866

DOI: $10.4000 /$ corpusarchivos.3866

ISSN: 1853-8037

\section{Publisher}

Diego Escolar

\section{Electronic reference}

Bárbara Betsabé Martínez, « Materialidad, creatividad cultural y práctica social: una etnografía de las cosas del pasado entre los habitantes de San Antonio del Cajón (Catamarca, Argentina », Corpus [En línea], Vol. 10, №. 2 | 2020, Publicado el 17 diciembre 2020, consultado el 29 diciembre 2020. URL http://journals.openedition.org/corpusarchivos/3866; DOI : https://doi.org/10.4000/corpusarchivos 3866

This text was automatically generated on 29 December 2020. 


\section{Materialidad, creatividad cultural y práctica social: una etnografía de las cosas del pasado entre los habitantes de San Antonio del Cajón (Catamarca, Argentina}

Materiality, cultural creativity and social practices: ethnography of things from the past among the inhabitants in San Antonio del Cajón (Catamarca, Argentina)

Bárbara Betsabé Martínez

\section{EDITOR'S NOTE}

Fecha de recepción del original: 20/08/2020

Fecha de aceptación para la publicación:

1 En abril de 2010 me encontraba realizando trabajo de campo en San Antonio del Cajón, ${ }^{1}$ Catamarca, Argentina. La familia con la que vivía y yo habíamos sido invitados a una señalada ${ }^{2}$ en Ovejería Chica, un área situada a varios kilómetros del poblado. Emprendimos el viaje a pie en cuanto despuntaron los primeros rayos de sol. En el largo camino cruzamos varias pircas derrumbadas. Yo sabía que eran restos de las casas de los indios que habitaron el valle antes de las poblaciones actuales, y habían perecido durante el diluvio, pues muchas veces los cajonistas, pacientemente, me habían narrado ese tiempo de su pasado. ${ }^{3}$ Los niños que venían con nosotros, hábiles en correr cerca nuestro y trepar las rocas que encontrábamos en el camino, fueron advertidos de no pisar las estructuras y, especialmente, de "no andar tocando algo que encuentren por ahí". Media hora de camino más tarde, hicimos un alto para descansar en un área rodeada de "mapas de los indios", que la arqueología denomina petroglifos. A sus anchas, los infantes ascendieron por ellos, imaginando que eran cimas de magnos 
cerros. Una hora después y completamente extenuados, arribamos al caserío que nos albergaría durante la ceremonia. Allí nos sentamos a desayunar algunos alimentos, rodeados por varios perros que peleaban por una comida que los dueños del lugar les sirvieron sobre morteros arqueológicos.

2 Aquella jornada, donde se mezclaron episodios de cierta evitación de los restos del pasado, junto a otros de abierto contacto y uso, me condujeron a preguntarme sobre los diversos modos en que los cajonistas socializan con los aspectos materiales del mundo anterior.

3 Recientemente, la relación entre las cosas del pasado y las poblaciones que viven cerca de ellas han motivado el interés de los investigadores por el uso político de los restos, que es explicado a partir del crecimiento y expansión de los movimientos de reivindicación indígena. ${ }^{4}$ Sin embargo, desde mi perspectiva, estos estudios parecen dejar de lado los diversos modos en que, en el contexto de procesos de etnogénesis como el cajonista, estos objetos y lugares son reutilizados de diversos modos, entre los cuales la apropiación política no siempre resulta un aspecto central. En este sentido, mi objetivo es mostrar cómo en San Antonio del Cajón, donde este estudio se realiza, los modos en que la población se vincula con ellos, se sustenta en los aspectos materiales e inmateriales de estos restos y cierto uso "práctico", entre otras cuestiones. ${ }^{5}$ Es decir, me interesa poner atención en los fenómenos de la cultura que corren en paralelo a otros, como las reivindicaciones políticas, pero que no son anulados cuando surgen estas últimas. De hecho, sostengo que estos procesos culturales se superponen articuladamente.

4 Para analizar estos tópicos me valgo de la idea de "creatividad cultural" acuñada por Thomas Abercrombie (2006) para dar cuenta del modo en que las poblaciones del área geográfica andina no conforman meros colectivos a los que el devenir se les impone. Por el contrario, son actores dinámicos que despliegan diversas facultades para establecer nuevas formas de acción frente a los cambios a los que se enfrentan. También resultan relevantes los aportes de los autores que desde las ciencias sociales problematizaron las relaciones entre las personas y las cosas. En este sentido, una contribución central es la publicación Esquema de una teoría de la práctica (Outline of a theory of practice) de Pierre Bourdieu (1972), en la que el autor sugiere desplazar el foco del estudio del mundo de las ideas hacia las cosas. Es que, desde su perspectiva, es precisamente la capacidad de los objetos para condicionar a los actores lo que nutre el medio por el cual las personas resultan seres sociales. Con la lente puesta en las oposiciones dentro del hogar, o la colocación de objetos, el autor propone que cada orden se vincula estrictamente con otro (el género o la jerarquía social, por ejemplo), mostrando cómo lo menos tangible se basa en lo más tangible. Mi trabajo también se nutre de los estudios sobre la sociabilidad de las cosas (Appadurai, 1991), que han mostrado cómo ellas pueden entrar y salir de distintos estados dentro de su trayectoria biográfica (Kopytoff, 1991). Estos me permiten considerar el modo en que la sociedad local puede hacer usos diferenciales o similares de sus cosas a lo largo de las generaciones. Sin embargo, aquí el centro sigue siendo la acción de las personas en estos procesos. La cuestión de la agencia brinda un giro conceptual y complementario a esta postura. Por ello, para estudiar los vínculos entre las personas y sus objetos también me interesa la perspectiva de Alfred Gell (1998), quien sugiere que las personas imputan una agencia social cuando se topan con un efecto. Es decir, propone la existencia de una tendencia a atribuir acción intencional a las personas y a las cosas 
(como cuando responsabilizamos a un ascensor que se avería con nosotros adentro, lo que resulta en nuestra ausencia en una reunión). Complemento estas ideas con los aportes que provee la teoría de la materialidad (Miller, 1998; Meskell, 2004). Un primer enfoque de esta perspectiva, a partir del abordaje de las cualidades estéticas y materiales de los objetos, es decir, de las formas y características que éstos poseen, sugiere que es posible establecer conexiones sutiles con la vida cultural y los valores vinculados a ellos, que las sociedades objetivan (Miller, 1998). Sin abandonar estos supuestos, también me interesa problematizar la distinción dualista entre sujeto y objeto, para bucear en los aspectos que quedan por fuera de esta distinción, como lo efímero y lo imaginario, entre otros (Miller, 1998). Ahora bien, como desarrollaré luego, la etnografía que vengo realizando desde el año 2003 muestra distintos sentidos sociales sobre los restos arqueológicos. Para analizar este punto, me valdré de los aportes de los autores que han focalizado no solo en la materialidad, sino en la idea de materialidades múltiples. Así, por ejemplo, Michael Rowlands (2005) ha sugerido que algunas personas y cosas pueden interpretarse como más materiales que otras, puesto que, a partir de las valoraciones sociales que se les aplican, son representadas con una mayor densidad. ${ }^{6}$ También Fred Myers (2005) focalizó en la pluralidad de materialidades y su grado relativo.

5 La temática propuesta requirió el uso de una serie de especificidades metodológicas. Por regla general, a lo largo de años de investigación pormenorizada, los antropólogos construyen un sólido corpus de información sobre lo que la gente hace y, en casos como el aquí estudiado, qué hace con sus cosas (Miller, 1998). El enfoque etnográfico otorga herramientas metodológicas que proveen una participación y una comprensión mucho más profundas sobre la vida social local que lo que las personas explicitan a través de sus dichos. Es que, desde los inicios de su formación, los investigadores comprenden que lo que la gente dice suele diferir sustantivamente de lo que hace (Geertz, 1997 [1973]). Por eso, uno de mis puntos de interés en este trabajo es considerar cómo es que la gente se vincula en términos materiales con los objetos del pasado, aun si jamás enuncia ningún interés en ellos. Es que muchas de las simbolizaciones y prácticas alrededor de estos objetos son marcadamente escurridizas (Martínez, 2015), pues una de las cuestiones centrales de la cultura material es que sus significaciones no se agotan en el plano lingüístico. Por ello, los intentos de comprender la imaginación nativa sobre el plano material limitándonos al aspecto discursivo nos encierra en un callejón sin salida, debido a que esta no suele ser descrita a viva voz (Tacchi, 1998). A la realización de una etnografía en San Antonio del Cajón se suma un problema adicional: allí la utilización de la entrevista, herramienta metodológica medular de la antropología, resulta problemática debido a que esta no existe como evento de habla. ${ }^{7}$ Teniendo en cuenta estas cuestiones, mi labor se apoyó principalmente en una extensa observación participante como herramienta central, aunque también se nutrió de algunas entrevistas abiertas de sesiones múltiples y de innumerables horas en las que caminar y hablar libremente de los tópicos que mis interlocutores eligieran era nuestra actividad prioritaria. ${ }^{8}$ En estos recorridos llevaba conmigo un grabador digital permanentemente encendido, lo que permitía obtener audios extensísimos en los que en ocasiones se registraron conversaciones y en otras no, pues el silencio primaba. Es decir, si bien algunos de los enunciados de mis interlocutores transcriptos aquí provienen de entrevistas, en su mayor parte corresponden al registro digitalizado oral de nuestra vida cotidiana. 
6 El trabajo se organiza en cinco secciones. En la primera, presento y describo la estructura económica y sociorreligiosa cajonista. Seguidamente, repaso las taxonomías nativas y las de la disciplina arqueológica sobre los sitios y objetos que se tratan en este artículo. En tercer lugar, a través de un ejemplo concreto y representativo, estudio los modos en que las trayectorias biográficas (Kopytoff, 1991) intervienen en la socialización de los lugares que poseen restos materiales del pasado. Con posterioridad, exploro las articulaciones entre las personas y los objetos del mundo anterior. Finalmente, en la quinta sección estudio las relaciones entre materialidad, creatividad cultural y estética sobre el pasado.

\section{Antecedentes y contexto local}

7 Ubicado al sur del valle Calchaquí, el valle del Cajón se extiende en sentido norte-sur a lo largo de aproximadamente $90 \mathrm{~km}$. Hacia mediados del siglo XV, con la anexión de noroeste argentino al imperio inca, los grupos locales sufrieron distintos procesos de cambio que, entre otros, implicaron una reorganización espacial $\mathrm{y}$, a veces, desplazamientos. Los estilos artesanales incas y los patrones arquitectónicos se transfirieron a las áreas conquistadas como una forma de control y dominación (Cremonte y Williams, 2007). Evidencias materiales de este proceso se hallan, por ejemplo, en Loma del Calvario y el Barrito, cerca de San Antonio del Cajón (De Hoyos, 1999) y campo de Huasamayo, La Lagunita y campo del Percal, en los alrededores de La Hoyada. Se ha propuesto, además, que el sitio La Maravilla, ubicado al norte de La Hoyada, pudo haber actuado como centro administrativo (De Hoyos, 1996a). Diferentes estilos cerámicos locales además del incaico podrían indicar la coexistencia de grupos multiétnicos bajo control estatal durante esta época (De Hoyos, 1996b).

Desde la perspectiva etnohistórica, para momentos posteriores a la dominación incaica se ha planteado que el valle Calchaquí sufrió una reconfiguración luego de las desnaturalizaciones de las poblaciones indígenas como consecuencia de la resistencia frente a la dominación española hacia fines del s. XVII (Lorandi y Boixados, 1987-1988). Hacia fines del s. XIX, la región se insertó en un proceso de urbanización e industrialización incipiente (Rutledge, 1987). Como resultado, numerosos pobladores migraron reconstituyendo su estructura identitaria, enmarcados en nuevos escenarios de encuentro, negociación y conflicto.

9 En la actualidad, la economía en el área del valle del Cajón es de subsistencia. La gente se dedica principalmente a la agricultura, al cuidado del ganado (cabras y ovejas) o al trabajo en la minería. Los ingresos de las unidades familiares se complementan con el dinero proveniente de los planes de asistencia financiera nacionales y provinciales. Dos veces por semana, una camioneta proveniente de la ciudad de Santa María, cabecera del departamento homónimo, abastece a los pobladores de algunos pocos productos, como alimentos y otros bienes. ${ }^{9}$ Durante la estación de lluvias el tránsito suele interrumpirse y los pueblos permanecen aislados.

10 En forma esporádica algunas unidades domésticas tienen ingresos económicos derivados de la asistencia a otros hogares, en particular en épocas de cosecha. También las personas ocasionalmente trabajan como peones o como guías para equipos de arqueólogos que realizan sus actividades en el área. La relación puede o no ser laboral, de modo que no siempre se encuentra mediada por dinero. Los arqueólogos a veces simplemente se limitan a solicitarles un simple bosquejo de una cartografía que los 
ubique en la zona, pues los cajonistas son expertos conocedores del paisaje. Ellos también les alertan de hallazgos fortuitos de restos materiales.

11 En la década pasada, San Antonio del Cajón ha sido escenario de disputas que ponen en escena el modo en que, desde mi perspectiva, la gente local negocia los procesos de cambio al interior de su sociedad. Diversos tópicos vinculados con el uso del medioambiente, las modificaciones edilicias y las expectativas que el turismo podría traer a la zona generaron una serie de discusiones que a los fines analíticos en un trabajo anterior denominé "panacea de la modernidad" y "proteccionismo localista" (Martínez, 2013, p. 83). Es decir, mientras algunos evaluaban las posibilidades que podrían ofrecer al pueblo nuevas actividades económicas, como el turismo, otro sector minoritario ponía el acento en la salvaguarda de sus recursos (especialmente botánicos). Esas controversias se prolongaron durante algunos años, pero paulatinamente fueron perdiendo vigor. En la actualidad, los desacuerdos comenzaron a centrarse en las valoraciones sociales sobre los movimientos de reivindicación étnica que se desarrollan tanto en San Antonio como en otras poblaciones del Valle del Cajón y que no han obtenido aún un consenso mayoritario.

12 Pero si algo describe el contexto local, es el modo en que los hitos del paisaje (v.gr. los restos arqueológicos) figuran inscriptos en la memoria social y en el presente cotidiano a través de narraciones cosmológicas y eventos mitoprácticos (Sahlins, 1988). Por regla general, estos son huellas del pasado, pero sus significaciones no se agotan allí. Pueden ser marcadores espaciales, sitios que expresan la trayectoria histórica, zonas de disputas diversas, condensadores de la dimensión ritual, áreas por momentos imperceptibles de tan familiares, entre otras.

13 En San Antonio del Cajón los aspectos materiales y los seres que pueblan el mundo se desarrollan a partir de una participación mutua en un sistema de relaciones de vital importancia (Bugallo, 2016), en el que las marcas en el terreno constituyen hitos comunicantes entre tiempo y espacio. Los intentos de clasificación de estos órdenes, así como de la visión del mundo cajonista, se han mostrado notablemente espinosos (Martínez, 2014a). En efecto, es complejo identificar ejes constantes de espacio y de tiempo, divisiones nítidas de dominios o identidades que no se alternen o difuminen. ${ }^{10}$

\section{Clasificaciones culturales}

14 Los restos arqueológicos son parte constitutiva del área. Se encuentran por doquier a la vera de los caminos y en las sendas de pastoreo. En diversos momentos de la vida diaria, cuando los pobladores excavan el suelo por distintas razones, este material del pasado emerge incluso en sus propias fincas. En San Antonio del Cajón, la utilización contemporánea del material arqueológico es frecuente. Ahora bien, de la gama de cosas del pasado disponibles, solo algunas se consideran aptas para ser reapropiadas en la vida cotidiana. Por otra parte, la misma cosa del mundo anterior (o sitio, en términos arqueológicos), puede considerarse relevante en cierto período, pero no en otro. También, un objeto puede ser destacado para una persona, pero resultar poco relevante para otra. Estas variantes en los sentidos de los objetos exponen las dificultades para establecer dominios clasificatorios permanentes (Martínez, 2014a). Sin embargo, a los fines analíticos, podemos realizar una primera aproximación ilustrando algunos modos en que el lenguaje disciplinar, corrientemente utilizado en las publicaciones científicas, difiere de la narrativa local con la que la gente describe su mundo. 
15 En esta línea, taxonomías como sitios y objetos arqueológicos son propias de la disciplina antropológica. Y si bien los cajonistas saben a qué se refiere una persona foránea cuando menciona estos tópicos (pues como he adelantado la presencia de arqueólogos es frecuente en el área), esas palabras no suelen utilizarse en las conversaciones entre pobladores. La gente reserva otras palabras para hablar sobre las cosas del pasado.

16 En 2009, mientras nos encontrábamos en la cima de un cerro observando el paisaje local, pregunté a Reino Condorí, una persona muy prestigiosa entre los pobladores en virtud de su conocimiento pormenorizado de la geografía local, sobre las estructuras arqueológicas que veíamos desde allí.

Más para arriba, adonde viene la pirca que se termina, ahí es donde le digo yo que donde hay muchos antigales (...) Nosotros le decimos los antigales, donde hay mucha choza, digamos, dicen que han vivido los indios le decimos antigales. Lleva el nombre de antigal. En Ovejería por ejemplo hay una parte que le dicen la zona antigal, nosotros le decimos antigal. (Reino Condorí, San Antonio del Cajón, 2009).

Según indicó aquella vez don Reino, la palabra antigal refiere de forma aproximada a aquello que los arqueólogos llamarían sitio arqueológico. También durante aquella jornada me explicó que los objetos del pasado se agrupan genéricamente bajo el nombre de las cosas que quedaron de los indios (o las cosas de los indios, aunque este término en algunas ocasiones también se usa para los sitios). De modo puntual, las personas mencionan a los objetos con el sustantivo que le da nombre (por ejemplo, muyuna).

18 La denominación antigal se extiende en buena parte del noroeste argentino. Diversos trabajos han mencionado su carácter "potente" y "peligroso" (Lanusse, 2009; Fontes, 2020) sugiriendo, sin embargo, que esto puede ser "perceptible en ciertos momentos" (Lema y Pazzarelli, 2005). Algunos antigales parecen haber sido olvidados, pues han quedado por fuera de la acción ritual o de la memoria social (Pazzarelli y Lema, 2018). En algunas versiones, se encuentran ligados a un mundo anterior, presolar, habitado por gente con rasgos y personalidades diferentes a las actuales (Rivet y Tomasi, 2016). En el caso de San Antonio también resultan de una humanidad anterior que es a veces mencionada como antecesora de las personas que hoy habitan el área. En la narrativa local, ambas poblaciones son fenotípicamente similares.

19 La socialización entre las personas y las cosas del pasado, las significaciones que se les asignan y los modos en que participa la trayectoria histórica local no intervienen de modo homogéneo, como analizaremos en los párrafos siguientes.

\section{Devenir histórico, negociaciones locales y telón de fondo}

He apuntado en otro sitio (Martínez, 2014b) que en San Antonio del Cajón el paisaje condensa nociones sobre la geografía, la memoria histórica, los mitos y las prácticas culturales. Es que transitar el paisaje no es un acto neutral. Moverse a través de él no es solo conectar un lugar con otro, es trasladarse a través del tiempo (Lecoq, 1987). Así como en la construcción de los objetos existe una apropiación de lo natural, de la materia que es transformada y resignificada, el paisaje también es apropiado, valorado y clasificado, forma parte del sistema mítico y es creado en el habitar (Ingold, 2000). En el noroeste argentino en particular, el paisaje ha sido moldeado por una densa red de 
intercambios y obligaciones recíprocas. Las personas utilizaron las pericias y la infraestructura de sus antecesores para sostener y crear nuevas formas de movilidad y alianza, que cobraron nuevos sentidos con el advenimiento de los incas y los españoles. Por tanto, este paisaje puede entenderse como una "regionalidad de tiempo profundo" (Lazzari, 2011, p. 180). Por ello, lejos de constituir un plano inmutable, resulta una instancia de gran dinamismo. Más aún, en la actualidad las personas organizan el paisaje a través de "mapas orales"11 (Wright, 2008; Martínez, 2014b) que reflejan heterogéneos y fugaces momentos de la vida cotidiana. En este contexto, uno de los lugares clave de San Antonio del Cajón es un antigal que la gente llama Loma del Calvario.

Este se encuentra al este del plano central, a 200 metros de la plaza y de la escuela. Se halla formado por dos hileras de estructuras que la narrativa arqueológica ha atribuido a los períodos Incaico y Formativo (De Hoyos, 1996a). Una, al norte de la colina, posee diez recintos, mientras que la que se encuentra al sur, aún mantiene once (De Hoyos y Williams, 2017). Los modos en que la gente se vincula con los restos del pasado en general, y con la Loma en particular, descansan en una compleja articulación de factores temporales, rituales y utilitarios. Como otros hitos socialmente significantes, posee distintos sentidos de acuerdo con el momento histórico, los ciclos diario y anual, y las acciones que la gente realiza, como el tránsito hacia el área de pastoreo o la acción ritual. Además, ciertos sentidos pueden ser relevantes en un período, y en otros pierden vigencia momentáneamente. Esta afirmación es importante porque nos conduce a la idea de que las formas en que la gente se relaciona con las cosas del pasado no es unívoca, sino diferencial y capaz de atravesar diferentes fases, aun en lapsos acotados. Desarrollaré estas ideas a través de varios ejemplos, centrados en un mismo antigal, la Loma, en razón de las posibilidades explicativas que este ofrece.

Para la gente de San Antonio del Cajón, durante buena parte del año la Loma conforma un sitio de paso hacia los terrenos de pastoreo ubicados al oeste del poblado. Y aunque esas tareas requieren de un pormenorizado conocimiento del territorio, en ese desplazamiento la Loma constituye un lugar de tránsito, ${ }^{12}$ que a lo lejos señala la salida o el arribo al poblado, pero que no conforma un horizonte de sentidos más allá de cierta ubicación a escala espacial. En este punto de mi trazado analítico de la relación de los cajonistas con sus cosas del pasado, la Loma conforma un horizonte que, aunque inmediato y familiar, no resulta relevante para el entramado social pues no se constituye como lugar de socialización (Rusell, 2018). Cuando la gente sale de pastoreo, la Loma forma un entorno, una especie de "telón de fondo" o "textura de contexto" para su vida cotidiana, que en esos momentos no tiene nada de especial (Tacchi, 1998). Durante estos lapsos de la vida social, este sitio (como otros similares), están allí como parte del paisaje, conformando sitios de paso. No los evitan ni se les acercan, pues no tienen el menor interés en ellos ni les prestan atención. Este telón, a nivel personal o social puede evocar otros tiempos, otros lugares e incluso otros estados de ánimo (Tacchi, 1998).

El modo en que los cajonistas socializan con este antigal es sustancialmente diferente en un momento clave del ciclo ritual anual: la Semana Santa. Pero para comprender este período, es necesario ahondar en la trayectoria biográfica del cerro (Kopytoff, 1991), la historia local y las apropiaciones rituales del territorio. La etnografía ha mostrado que a inicios del s. XX, sacerdotes itinerantes, probablemente utilizando antiguas rutas comerciales, comenzaron una incipiente 
evangelización en el área, ${ }^{13}$ tal como surge de los archivos parroquiales (Libro de Fábrica, 1924). Entre estos documentos no figuran anotaciones sobre la Loma más que para puntualizar la realización allí de alguna que otra misa. De modo que fueron las narrativas de los miembros del poblado las que fundaron las bases para analizar los modos en que la historia local le dio forma al sitio ritual. A partir de ellas supe que en la década del 70, en el sector superior de esta prominencia del terreno se comenzó a construir un vía crucis. Este proceso implicó una compleja serie de decisiones a nivel local. En la ladera norte se encuentra una casa y el conjunto de estructuras mencionado, actualmente utilizado para cultivo. ${ }^{14}$ La ladera sur, también con estructuras y terrazas, forma parte de la finca de otro poblador. En aquel período, ambos decidieron ceder en préstamo tanto la cima de la loma, como su propio trabajo físico. Además, propusieron la construcción de una senda con las diversas estaciones que componen un calvario, algunos asientos de piedra y un altar. La medida tuvo amplio consenso entre los pobladores. El propietario de la ladera sur por ese entonces era parte (tal como hoy en día) de la estructura de poder religioso local. Según me contó, habló desde el púlpito de la capilla durante diferentes encuentros entre vecinos para interesarlos en la relevancia de esta construcción. Las demás autoridades religiosas participaron activamente en la toma de decisiones. Así, los acuerdos entre los propietarios del terreno, los vecinos y el poder religioso constituyeron componentes centrales para la conformación de un nuevo lugar ritual: el calvario.

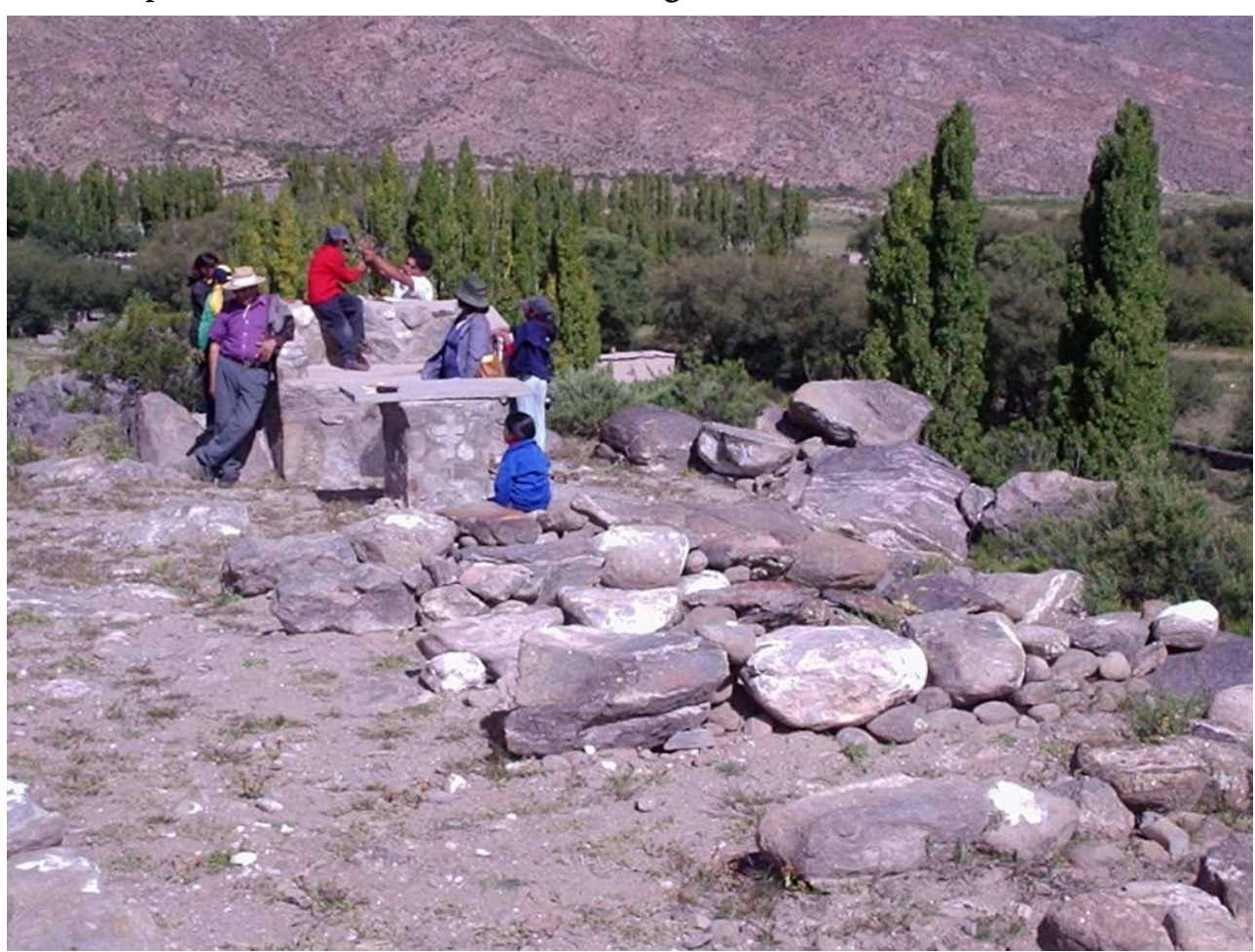

Fig. 1. Altar e hileras de bancos construidos con rocas en la Loma del Calvario. Atrás, el pueblo de San Antonio del Cajón. Foto de la autora.

Los momentos del horizonte histórico descritos no agotan las características del lugar. Las ceremonias que en ella se desarrollan durante Semana Santa son cruciales para comprender sus sentidos. 
A nivel local, el orden cosmológico se organiza en virtud a una perpetua batalla entre los poderes de Dios, Cristo y el Maligno, que he descrito en otro sitio (Martínez, 2014a). Es en Semana Santa, sin embargo, el período en que los cajonistas se ven especialmente amenazados, en virtud de la muerte de Cristo, cuando el Maligno recobra algo de sus fuerzas. Por eso, las personas se apoderan del plano del poblado mediante procesiones en las que el sacrificio corporal es la prueba de su colaboración con los poderes divinos. También se organizan batidas de caza de animales asociados al Maligno (como las serpientes y las lagartijas), para así obtener indulgencias en este momento incierto de la contienda cosmológica. Y si bien la serie de procesiones es amplia, compleja y se realiza durante varios días, dibujando en el plano del poblado diversos vía crucis, el derrotero ritual culmina en la Loma del Calvario. Esta es la única construcción material de índole religiosa (más allá de algunas pequeñas ermitas) que, además de la capilla, es capaz de albergar un gran número de personas. Además de las diversas estaciones del vía crucis, los cajonistas erigieron allí, con rocas y cemento, un altar y varias hileras de bancos en los que pueden sentarse durante las celebraciones. En ese lugar terminan de efectuarse las peticiones sobre la terapéutica, las normas morales y la protección familiar que marcan esta fecha.

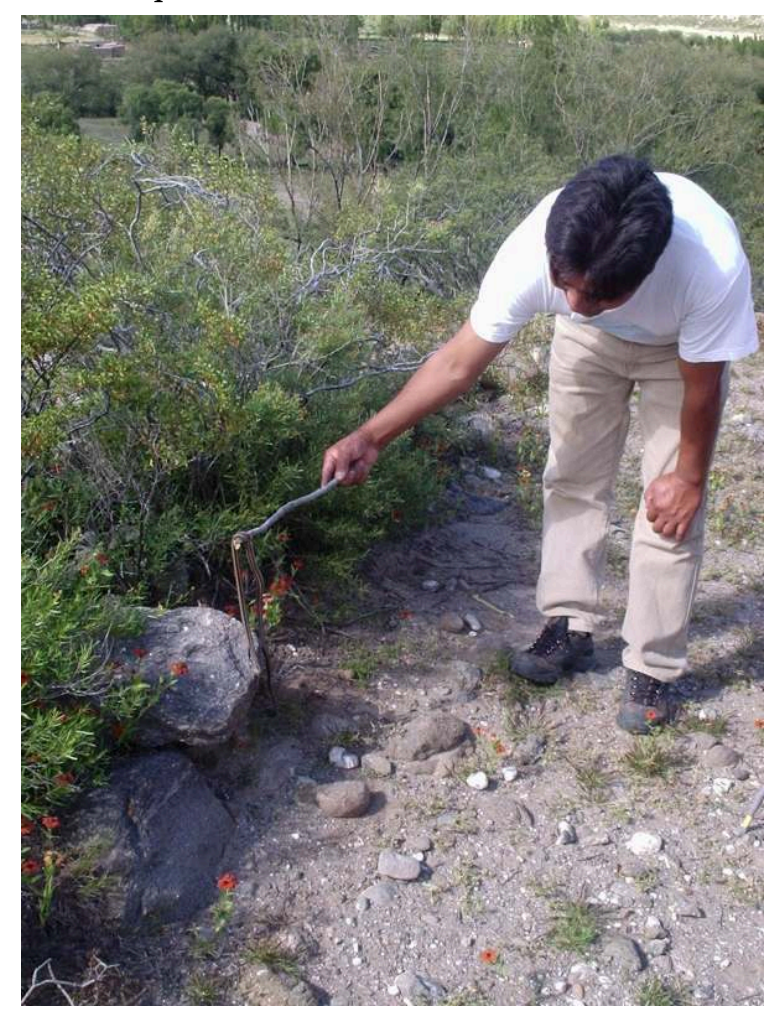

Fig. 2. Caza de serpientes durante Semana Santa. Foto de la autora.

Por otra parte, las significaciones sociales también pueden cambiar al compás del ciclo diario. ${ }^{15}$ En efecto, en ocasiones la gente que habita la ladera norte de la Loma del Calvario ha escuchado sonidos y ha visto algunas luces cerca de las estructuras vecinas. Cuando eso ocurre, se limitan a guarecerse en sus casas, tal como lo harían ante la posibilidad de la presencia de cualquier ser nocturno (como, por ejemplo, los muertos). Estas manifestaciones parecen incrementarse durante agosto. Es que este mes provee a las personas de las circunstancias propicias para hacerse de los tapados ${ }^{16}$ que se encuentran bajo la superficie de la tierra.$^{17}$ Durante ese lapso la tierra tiembla, se abre y 
el mundo se encuentra convulsionado. Entonces, los tesoros son expuestos, favoreciendo que la gente acceda a ellos. ${ }^{18}$ experimentado de manera diferente por diversas personas, o incluso por la misma persona en distintos momentos, así como los acuerdos o mutaciones atadas a las contingencias históricas y culturales (Bender, 2006). Es decir, expone articulaciones entre la vida de las personas y la vida de las cosas en San Antonio del Cajón, en el que el horizonte histórico local, y ciertos momentos del ciclo diario y anual (por ejemplo, en Semana Santa, agosto o durante algunas noches), resultan cruciales. Rowlands (2005) ha sugerido que algunas personas o cosas pueden verse más materiales que otras. Esta materialidad relativa llama nuestra atención, mientras casos similares solo se mantienen en la periferia de nuestro interés. En este sentido, sugiero que la Loma resulta más material, en el sentido de más visible, significante y poderosa (por ejemplo, en su rol dentro de la contienda cosmológica descrita). Pero eso ocurre solo en algunos lapsos, mientras que en otros esta visibilidad se desvanece. Por ello, ejemplifica el modo en que hitos como este son socialmente significantes, aunque no siempre con la misma intensidad ni para las mismas acciones, mostrando la imposibilidad de separar (más que analíticamente) las formas en que la gente socializa con sus objetos, sin generar contrastes demasiado marcados, que no respondan a la realidad local.

\section{La cuestión de la vida cotidiana}

Los paisajes tienen el poder de actualizar en el presente diferentes niveles de temporalidad, otorgando vías para el análisis de los modos en que las personas organizan sus mundos sociales discursivos y no discursivos, vinculándose a ellos (Ingold, 2000). Además, también encarnan experiencias profundamente sentidas, pero a veces levemente expresadas, pues las significaciones no pueden ser enteramente impresas en el terreno. Este orden de la experiencia no solo está sujeto a la valoración individual, sino también a subjetividades comunitarias, de modo que la relación que se teje es culturalmente mediada (Lazzari, 2011).

31 Si bien las cosas del pasado poseen una reactualización que le imprime nuevas significaciones, es posible que no siempre sus usos difieran drásticamente de los de hace siglos. Por tanto, no podemos descartar que ciertas cosas posean un marco de referencia cultural para un uso de larga data, a su vez moldeado por sistemas de clasificación, valoración o descarte. Por supuesto, la etnografía solo puede dar cuenta de las cuestiones del presente. 

viene de preguntarnos ¿qué rol cumplen las cosas en la vida cotidiana? Es decir, siguiendo a Miller (1998), ¿qué hacen las personas con las cosas? En nuestro caso, como veremos, las formas y las propiedades de los materiales con que están hechos los objetos del pasado juegan un rol crucial en las valoraciones y usos sociales contemporáneos. Como sugiere Ingold (2007), lo que importa aquí no son necesariamente los objetos materiales, sino la sustancia que los compone, sus propiedades, los flujos de materiales y las posibilidades de acción que brindan. Es decir, lo que se busca es utilizar estas cuestiones que los objetos condensan, como marcos interpretativos para el análisis de la sociedad.

Entre los objetos de pasado que la gente encuentra dispersos, los más relevantes (en razón de su buen estado de conservación), son los morteros (fijos o móviles, como explicaré), las pecanas, las muyunas (o torteros), ${ }^{20}$ las urnas funerarias, los pucos y las parteras. ${ }^{21}$ Los morteros fijos son un conjunto de oquedades de diverso tamaño que se encuentran tallados en grandes y firmes rocas. El resto de los objetos puede ser transportado y utilizado para diversos fines. Los morteros móviles, como veremos, suelen ser trasladados a los hogares para molienda. Las pecanas son también objetos de piedra, con concavidad marcadamente menor que el mortero, igualmente destinados a procesar alimentos. Por su parte, las muyunas son discos de arcilla o piedra utilizados como contrapeso del huso en el proceso de hilado. Además, sirven como tope para la lana. Las ollas o urnas funerarias (utilizadas para contener cuerpos) y los pucos (cuencos o tapas que, pegados a las urnas, protegían el entierro), ${ }^{22}$ en la imaginación local se encuentran asociados con los muertos, y son los que menos frecuentemente encontramos en los hogares. ${ }^{23}$ Las parteras, unas rocas de gran tamaño sobre las que, según la gente de San Antonio del Cajón, las mujeres en situación de alumbramiento del tiempo de los indios se arrodillaban para parir, poseen más bien un rol ornamental. ${ }^{24} \mathrm{Aquí}$ me interesa indagar en los tres primeros, es decir, en los morteros, las pecanas y las muyunas, pues poseen un papel relevante en las actividades diarias.

En marzo de 2010 acompañaba a doña Telma y a sus nietos a pastar las cabras. Debido a que la entrevista era una herramienta metodológica cuando menos forzada, tal como señalé con anterioridad, transitar el paisaje y mientras tanto conversar informalmente resultó una tarea bastante más fructífera. Más aún, imponer una agenda de temáticas de interés solía constituir un despropósito, pues la conversación, especialmente en el caso de doña Telma, discurría por los tópicos de la vida social que ella prefería. Aquella mañana decidió enseñarme a hilar, que es una actividad que suele realizarse en paralelo con el pastoreo. Cuando cruzamos el río en dirección a sus terrenos, que se ubican al este del poblado, hicimos un alto en un conjunto de morteros que se hallaban sobre una impronta rocosa. Mientras los niños corrían y jugaban a nuestro alrededor, ella se dedicó a moler maíz, ayudándose con una piedra del lugar. Luego de explicarme el procedimiento, simplemente envolvió los restos y seguimos nuestro camino. No era la primera vez que doña Telma utilizaba ese sitio para molienda y tampoco era la única persona que lo hacía. Como me explicó entonces, y yo misma pude presenciar con posterioridad, buena parte de la gente que posee sus terrenos de apacentamiento en esa ladera utiliza ese sitio para desintegrar granos. Seguimos nuestro camino hasta llegar a destino. Allí nos sentamos sobre una roca mientras la mujer sacaba el huso de su bolsillo. Aquella vez me contó que encontró su muyuna cuando era niña, mientras se 
dirigía al río a lavar la ropa. Y aunque tiene otras que ella misma confeccionó, prefiere esa, porque es más “churita, ${ }^{25}$ no se rompe, esta (calidad en la) piedra no se ve por ahí".

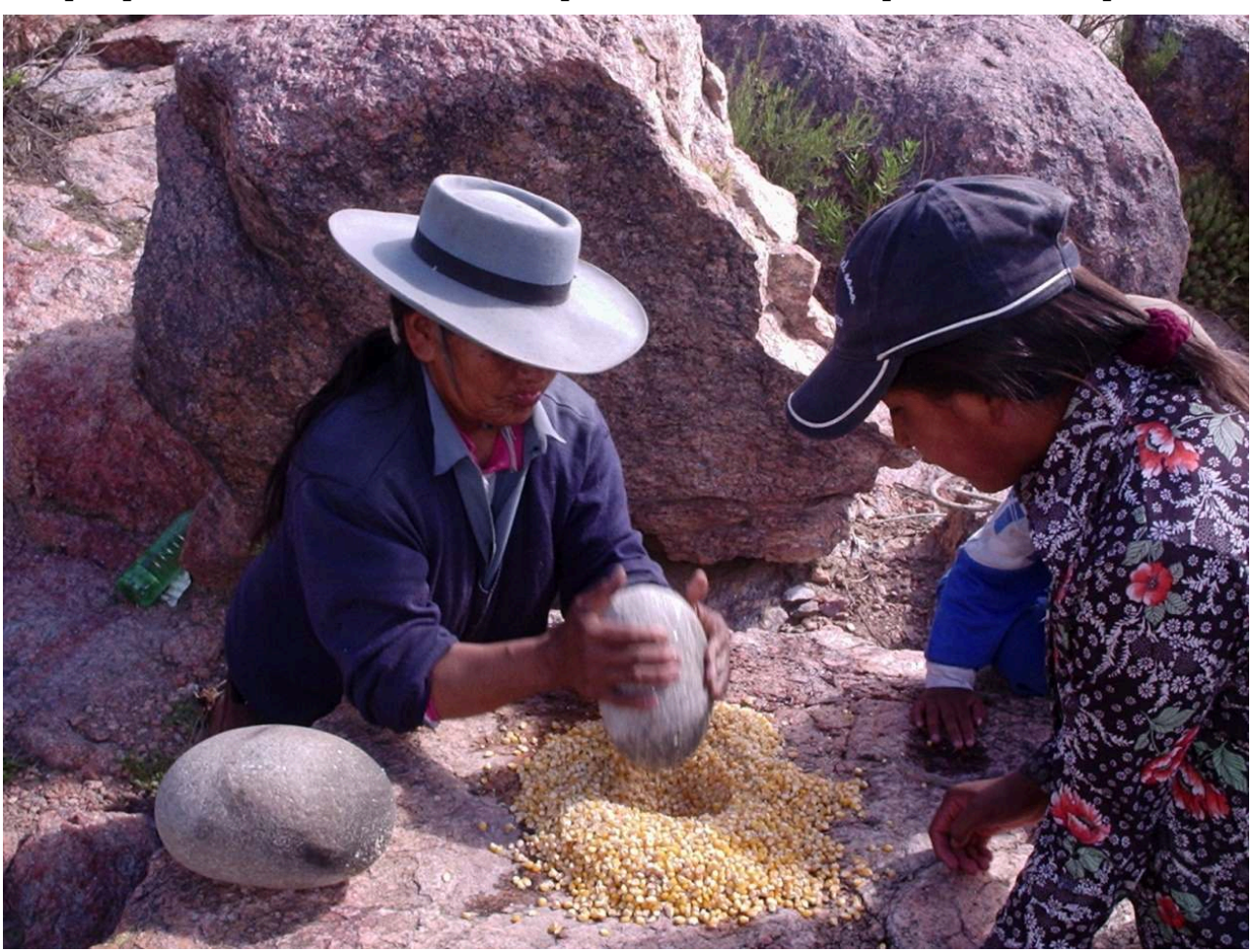

Fig. 3. Doña Telma y su familia procesando maíz en el mortero fijo. Foto de la autora. ayuda de una mano, es decir, una roca de una proporción que sirve para aplastar, y que suele escogerse entre las que están en el suelo (donde hay algunas apartadas para este fin), la gente realiza un movimiento de arriba hacia abajo que les permite procesar alimentos como el charqui, el maíz y el trigo. El mortero desarma los ingredientes, lo que lo vuelve especialmente apto para la preparación de alimentos que requieren la desintegración de los granos, la carne, etc.

Por otra parte, las cualidades materiales provenientes del tipo de roca que componen las muyunas del tiempo de los indios resultan clave para comprender su utilización contemporánea. Aunque las personas en la actualidad podrían confeccionarlas, los sentidos de aquellas que provienen del tiempo anterior las definen como más fructíferas para la labor cotidiana, en virtud de su durabilidad y eficacia.

rutinas diarias comprenden también a los morteros móviles. La mayoría de ellos es hallada por la gente en su recorrido, transportada y utilizada para fines variados. Por supuesto, sirven a los mismos fines que los fijos. Pero, además, su forma cóncava, el material rocoso con que están confeccionados y las posibilidades de traslado que brindan de un lugar a otro dentro de la finca, los vuelve especialmente aptos para depositar cosas por períodos breves de tiempo (como la sangre durante el carneo, o el alimento de los perros). Como el resto de las cosas del pasado mencionadas aquí, hasta el momento la etnografía no muestra que su uso se encuentre asociado al ciclo diario, anual, al simbolismo de la ritualidad vinculada al carneo, o a algún otro elemento de la vida social que exceda el uso práctico. 


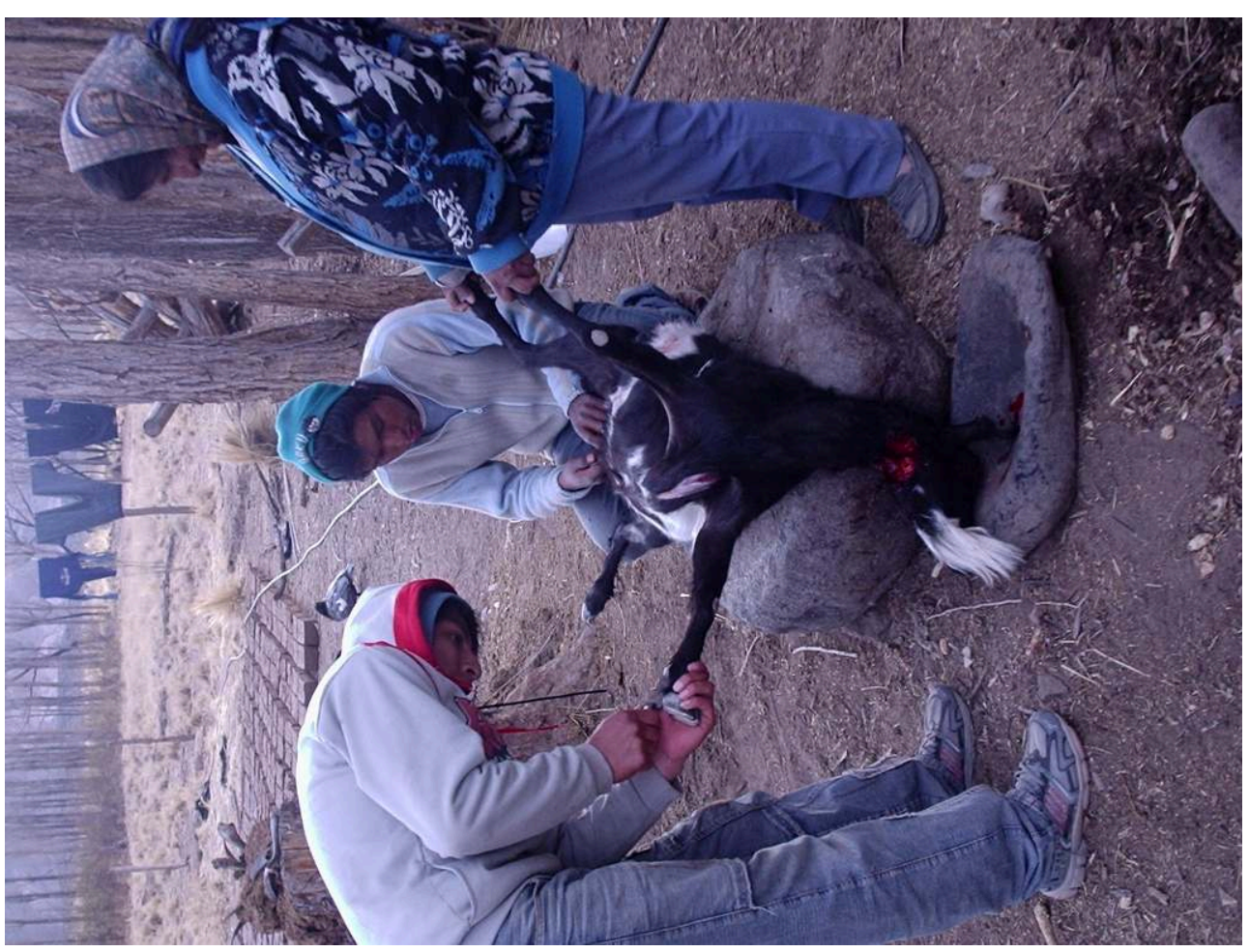

Fig. 4. Mortero utilizado como receptáculo para la sangre durante el carneo. Foto de la autora.

La pecana ${ }^{26}$ participa de cualidades materiales similares. Puede tener hasta $40 \mathrm{~cm}$ de alto, y alcanza los $70 \mathrm{~cm}$ de ancho aproximadamente. Se emplea ejerciendo un delicado balanceo con otra piedra redondeada, otra vez llamada mano, aunque más larga y ancha, presionando levemente en un movimiento que va de atrás hacia adelante, de tipo pendular, o ejerciendo su propio peso sobre el alimento. Si bien tanto el mortero como la pecana sirven para procesar los alimentos, sus funciones difieren. Por tanto, uno $u$ otra se utilizan de acuerdo al resultado que se busca. Así, por ejemplo:

Para hacer la humita, le llaman pecanear el choclo. Lo cortan, lo separan con un cuchillo al maíz el marlo, lo llevan a la pecana y lo pecanean. Ese trabajo no se lo puede hacer en el mortero, porque el mortero se lo va a desarmar del todo, lo va a desarmar bien. En cambio, la pecana no lo desarma completamente a lo que quiere moler. Es decir que con la pecana es más livianito el proceso. Con el mortero es moler, con la pecana es quebrajear. Con el mortero muelen el charqui, o sea la carne seca, la muelen y con eso arman el locro, y toda la comida típica de acá (Walter Albarracín, Santa María, 2020).

Como en cualquier contexto social, en San Antonio de Cajón algunas cosas importan más que otras. Incluso puede decirse que ciertos objetos son más materiales que otros, pues poseen una considerable solidez, rol social, e incluso papel como objeto colectivo (Miller, 2005). Los morteros, las pecanas y las muyunas se asocian a un prestigio que es del pasado (en el sentido de la durabilidad y resistencia de algunas cosas del tiempo de los indios, cuya valoración no está exenta de ambigüedades), son más materiales en el sentido de más visibles; son prácticas y útiles. La gente local valora especialmente sus cualidades estéticas y materiales, su materia prima y las posibilidades de uso que brindan. Es decir, más que en virtud de su valor como objeto de creación del pasado, la vida cultural entre las personas y estos objetos se tejen en virtud de su valor como herramienta para la vida cotidiana. 

ha señalado que la importancia de la inmaterialidad exacerba la materialidad (Miller, 2005) y San Antonio del Cajón no es una excepción a estos procesos. Aquí la relevancia de la relación con los antepasados que protagonizaron el tiempo de los indios, las fuerzas y habilidades asociadas con ellos nutre la experiencia actual con sus objetos. $\mathrm{Si}$ los objetos crean relaciones sociales, ¿deberíamos encontrar una articulación entre los objetos y las demandas étnicas? Creo que en el contexto actual los objetos no están desvinculados de los aspectos inmateriales del pasado, pero tienen una razón menos grandilocuente: están al servicio de la vida cotidiana.

41 Desde mi perspectiva, la gente articula un uso político de las demandas étnicas que ancla en reclamos de derechos y autonomía, con formas (quizás en algunos casos de larga duración) de relacionarse con los objetos. En este entramado de formas materiales e inmateriales han sido moldeados, en diferentes momentos, por factores como las formas (frecuentemente ambivalentes) de relacionarse con los habitantes del tiempo de los indios, los artilugios para esconder su indigeneidad, los cambios contextuales que favorecieron nuevas formas de pensar su pasado, las cambiantes relaciones de alteridad con los contextos mayores como el de la ciudad de Santa María, entre otros aspectos.

\section{Estética, materialidad y creatividad cultural}

Como describí con anterioridad (Martínez, 2013), los imaginarios sobre la modernidad y la protección de los recursos han constituido ítems centrales en las disputas que la gente de San Antonio del Cajón ha tenido hace algunos años. Las disidencias recorrieron numerosos tópicos, en un abanico que implicó desde la expoliación de sus vegetales por parte de los habitantes de la ciudad de Santa María, hasta cambios edilicios en la localidad.

Las posibilidades monetarias que brinda el turismo también fueron un factor de discusión relevante. Los rimbombantes anuncios efectuados en el año 2007 sobre la construcción de un dique en la localidad vecina de La Hoyada impulsaron la edificación de una hostería para albergar a los futuros visitantes. En el seno de la familia propietaria se sucedieron conversaciones sobre las características estéticas que debía tener el lugar, apelando mucho más a aquello traducible como indígena, habilitado por el patrón decorativo de los turistas que llegarían al lugar, que a las elecciones personales de sus poseedores. Aquel albergue operó más bien como una "metáfora sólida" (Tilley, 1998) ${ }^{27}$ de la imaginación local sobre los anhelos de los futuros visitantes.

Pero para otros, el dique también traería problemas. El posible traslado de la población, el abandono de sitios rituales significativos y la destrucción del material arqueológico preocupó a algunos sectores de la población. Finalmente, con el correr del tiempo el proyecto del dique perdió vigor entre la clase política, la hostería no se concluyó y el movimiento turístico no se inició. Los imaginarios sobre la inserción de San Antonio del Cajón en el flujo translocal paulatinamente dejaron de cruzar las conversaciones.

Años después surgieron en este contexto procesos de reemergencia étnica llevados a cabo por algunos grupos locales, quienes iniciaron sus propias demandas de autonomía y derechos. En este plano, a través del tiempo las discusiones se deslizaron a tópicos como patrimonio cultural originario. La organización y los patrones estéticos de 
comunidades cercanas, como Quilmes y Amaicha, sirvieron como modelos sobre los que comenzaron a elaborarse ideas y acciones a seguir. En varios sentidos, este devenir fue impulsado por una multiplicidad de agentes del Estado-nación ${ }^{28}$ más propensos a identificar expresiones culturales esencializadas ${ }^{29}$ que a revisar el modo en que se expresan estas cambiantes sociedades. Estas poblaciones se habían desarrollado por siglos de cara a su pasado, apropiándose y siendo apropiados por este a través del sistema mítico, las clasificaciones temporales y los mapas orales, entre otras manifestaciones de creatividad cultural (Abercrombie, 2006). Ahora, optaron por organizar una política y una estética indígena que respondiera a las demandas de los actores gubernamentales y a aquellos que, de poblaciones cercanas, cuestionaran su identidad "verdadera". Así, debieron mutar a un repertorio cultural "identificable" y sistematizable. En este contexto, las interconexiones entre la sedimentación de las experiencias previas (Lazzari, 2012, p. 3), el horizonte histórico local y las disputas dentro de la sociedad sobre las decisiones estéticas a seguir expusieron el modo en que el patrimonio arqueológico resulta de relaciones estructuradas y estructurantes de los paisajes y los agentes sociales (Jofré et al., 2008).

Es decir, en las dos últimas décadas, el devenir histórico vinculado a los restos arqueológicos suscitó, al inicio, un interés sustentado por la protección que debía tener frente a los avances turísticos. Pero la decadencia del proyecto implicó que la temática perdiera relevancia hasta hoy en día, cuando es mencionado esporádicamente por algún poblador. No obstante, hasta el momento el movimiento de reivindicación étnica que se desarrolla en San Antonio del Cajón no parece tener especial interés por los objetos o sitios del pasado. Esto no debe sorprendernos, pues como vimos a lo largo del artículo, los restos arqueológicos, junto a los sujetos e ideas, se encuentran en una constante espiral de movimiento interrelacionado que reviste diferentes trayectorias e intensidades. Hasta hace poco tiempo, los posibles vínculos genealógicos con las personas que elaboraron los restos materiales del pasado eran en ocasiones ambiguos, cuando no estaban definidos en términos de ruptura. Es decir, los habitantes que poblaron el valle en el tiempo de los indios, desde la perspectiva local, en algunas ocasiones eran identificados como antepasados, mientras que en otras se los señalaba como miembros de un mundo anterior que guardaban lazos con el actual. Desde mi perspectiva, en estas formas de elaborar la identidad local jugaron un rol central los mecanismos de creación de la alteridad, de larga data, con los que la gente de San Antonio del Cajón fue definida por los habitantes de la ciudad capital, Santa María, y que figuran inscriptos en su memoria histórica. Hace apenas algunos años los tópicos indio y coya eran utilizados hacia ellos de modo despectivo (Martínez, 2013). Hoy son cuestionados, frecuentemente por esas mismas personas, en términos de su reivindicación como comunidad originaria. Los mecanismos continúan, mientras muta su contenido. $\mathrm{Y}$ aunque en otros contextos los restos del pasado han servido como piedra angular para forjar nuevas relaciones entre los actores sociales (Escolar, 2012), para restablecer instituciones o tramar vínculos con el estado (Canessa, 2012), el devenir cajonista es aún una página incierta.

\section{Consideraciones finales}

47 A partir de la idea de "creatividad cultural", propuesta por Abercrombie (2006) para el análisis de las sociedades del área geográfica andina, y de los aportes de la teoría de la 
materialidad, en este artículo revisé las prácticas sociales vinculadas a la Loma del Calvario, así como a algunos objetos del pasado (los morteros fijos y móviles, las pecanas y las muyunas) en San Antonio del Cajón. Para ello, sinteticé los trabajos académicos que antecedieron a mi etnografía, el universo sociorreligioso y aspectos taxonómicos generales.

Con relación a la reutilización de un sitio arqueológico, inicialmente he sugerido que el paisaje local contiene hitos que condensan la memoria histórica y la acción ritual, entre otras instancias de la vida social. Pero los sentidos sobre estos hitos mutan según las distintas etapas del ciclo anual y diario, las actividades cotidianas y el contexto histórico, entre otras. De hecho, a veces no constituyen más que un "telón de fondo" (Tacchi, 1998) para acciones que se llevan a cabo en su entorno inmediato. El caso del sitio arqueológico Loma del Calvario aquí presentado muestra cómo las valoraciones sociales sobre él se encuentran más ligadas a las negociaciones entre miembros de la estructura religiosa local que a demandas de autonomía étnica. En este caso, la imaginación cultural también involucra el ciclo anual y el ciclo diario. Y aunque algunas etnografías definen a los sitios arqueológicos como "potentes" y "peligrosos" (Lanusse, 2009; Fontes, 2020), la Loma del Calvario no resulta especialmente amenazante, y conforma la mayor parte del tiempo un mero escenario de otras actividades.

Por otra parte, mediante ejemplos concretos y representativos de objetos del pasado (es decir, los morteros, las pecanas y las muyunas), señalé las relaciones de utilidad que las personas poseen con las cosas en un contexto de escasez de recursos materiales. Así, sugerí que las apropiaciones van mucho más allá de una perspectiva ritual o etnopolítica. Es decir, mostré cómo sus características materiales hacen de ciertos objetos arqueológicos elementos óptimos para el uso práctico cotidiano. En este sentido, su uso contemporáneo parece responder más a su forma y características materiales que a otros aspectos de la sociedad cajonista, como los ciclos diario y anual, o el simbolismo relativo a la práctica de careo, por citar algunos ejemplos. Ello no implica que lo material se encuentre desvinculado de los aspectos inmateriales, pues los unos son condición de los otros.

Seguidamente ilustro cómo en el contexto cajonista contemporáneo, en el que los movimientos de reivindicación étnica cobran cada vez un lugar más relevante, la estética vinculada al pasado se discute al compás de los cambios contextuales y las articulaciones con el Estado-nación.

51 Pero las narrativas sobre el pasado y sobre el material arqueológico son categorías en permanente construcción, ligadas a procesos de creatividad cultural. Y aunque en la actualidad los sitios y objetos arqueológicos parecieran encontrarse al margen de los procesos de reivindicación étnica local, es posible que las dinámicas sociales pronto los pongan nuevamente en el tapete, pues nos muestran la complejidad con la que estas sociedades piensan, organizan y fundan interpretaciones creativas de su devenir. 


\section{BIBLIOGRAPHY}

Abercrombie, T. (2006). Caminos de la memoria y el poder. Etnografía e historia en una comunidad andina. Lima: IFEA/IEB/ASDI.

Ambrosetti, J. B. (1889-1890). Notas de arqueología Calchaquí. Boletín del Instituto Geográfico Argentino, 18-20, 163-187.

Angelo, D. (2005). La arqueología en Bolivia. Reflexiones sobre la disciplina a inicios del S. XXI. Arqueología Suramericana, 1 (2), 185-211.

Appadurai, A. (1991). Introducción: Las mercancías y la política del valor. En A. Appadurai, (Ed.), La vida social de las cosas: perspectiva cultural de las mercancías (pp.17-88). Cambridge: Cambridge University Press.

Bender, B. (2006). Place and landscape. En C. Tilley, W. Keane, S. Kuechler, M. Rowlands and P. Spyer (Eds.), Handbook of Material Culture (pp. 303-314). Londres: Sage.

Bourdieu, P. (1972). Outline of a theory of practice. Cambridge: Cambridge University Press. Bugallo, L. (2016). Wak'as en la puna jujeña. Lo fluido y lo fino en el diálogo con la Pachamama. En L. Bugallo y M. Vilca. (Comp.). Wak'as, diablos y muertos. Alteridades significantes en el mundo andino (pp. 111-161). Lima: Editorial de la Universidad Nacional de Jujuy-Instituto Francés de Estudios Andinos.

Canessa, A. (2012 diciembre). De la arqueología a la autonomía. El uso de restos precolombinos para forjar una nueva relación con el Estado en Bolivia. Nuevo Mundo, Mundos Nuevos, [On line]. Disponible en: https://journals.openedition.org/nuevomundo/6457

Clifford, J. (1995). Dilemas de la cultura. Antropología, literatura y arte en la perspectiva posmoderna. Barcelona: Gedisa.

Conforti, M. y Endere, M. (2012). La imagen de la arqueología y el patrimonio arqueológico en los medios de comunicación. Un análisis sobre la prensa gráfica local. Antípoda. Revista de Arqueología y Antropología, [On line], 14. Disponible en: https://revistas.uniandes.edu.co/toc/ antipoda/14

Cremonte, M. B. y Williams, V. I. (2007). La construcción social del paisaje durante la dominación Inca en el NOA. En A. Nielsen, M. C. Rivolta, V. Seldes, M. M. Vazquez y P. Mercolli (Eds.), Procesos Sociales Prehispánicos en el Sur Andino (pp. 207-236). Buenos Aires: Editorial Brujas.

De Hoyos, M. (1996a). La Hoyada. Un enclave de producción agrícola en el valle del Cajón. Provincia de Catamarca. Revista del Museo de Historia Natural de San Rafael, XXV (4), 273-293.

De Hoyos, M. (1996b). Centros de producción agrícola en el Valle del Cajón. Revista del Museo de Historia Natural de San Rafael, XXIV, 3 (4), 295-317.

De Hoyos, M. (1999). Asentamiento Inka en San Antonio del Cajón (Departamento de Santa María. Catamarca). En Actas del XII Congreso Nacional de Arqueología Argentina 1 (pp. 194-198). Universidad Nacional de La Plata.

De Hoyos, M. y Williams, V. (2017). Abran kancha... Una variante de recinto perimetral compuesto en el Noroeste argentino. Estudios Atacameños [On line], 55. Disponible en: https:// revistas.ucn.cl/index.php/estudios-atacamenos/article/view/2661 
Escolar, D. (2012, diciembre). El vórtice soberano: salamancas, políticas de lo extraordinario y la emergencia de los huarpes en Cuyo, Argentina. Nuevo Mundo, Mundos Nuevos. [On line]. Disponible en: https://journals.openedition.org/nuevomundo/64570

Fabian, J. (1983). Time and the other. How anthropology makes its object. Columbia: Columbia University Press.

Fernández Juárez, G. (1996). El mundo «abierto»: agosto y Semana Santa en las celebraciones rituales aymaras. Revista Española de Antropología Americana [On line], 26. Disponible en: https://revistas.ucm.es/index.php/REAA/article/view/REAA9696110205A

Fontes, C. (2020). Encuentros con dueños, duendes y diablos: intersubjetividad, movimiento y paisaje en los caminos de la Quebrada de Humahuaca. Revista Ciencias Sociales y Religión. 22, 1-25.

Geertz, C. (1997 [1973]). La interpretación de las culturas. Barcelona: Gedisa.

Gell, A. (1998). Art and agency: an anthropological theory. Oxford: Oxford University Press. Ingold, T. (2007). Materials against materiality. Archaeological Dialogues [On line], 14 (1), 1-16. Disponible en: https://www.cambridge.org/core/journals/archaeological-dialogues/article/ materials-against-materiality/018549D1821007A427BA0324E1FF03C5

Ingold, T. (2000).The perception of the environment. Londres: Routledge.

Jofré, C., Biasatti. S., Compañy, G., González, G., Galimberti, S., Najle, N. y Aroca, P. (2008). La cayana: entre lo arqueológico y lo cotidiano. Tensiones y resistencias en las versiones locales del "patrimonio arqueológico" en el norte de San Juan. Relaciones de la Sociedad Argentina de Antropología. [On line], XXXIII. Disponible en: http://www.saantropologia.com.ar/wp-content/ uploads/2015/01/Relaciones\%2033/07\%20 Jofre\%20 final.pdf

Kopytoff, I. (1991). La biografía cultural de las cosas: la mercantilización como proceso. En A. Appadurai (Ed.). La vida social de las cosas: perspectiva cultural de las mercancías (pp. 89-124). Cambridge: Cambridge University Press.

Lanusse, P. (2009). Mito, historia e identidad en Cachi (Valles Calchaquíes, Salta). Avá. [On line], 16. Disponible en: http://www.ava.unam.edu.ar/images/16/pdf/ava16_lanusse.pdf

Lazzari, M. (2011). Tangible interventions: the lived landscapes of contemporary archaeology. Journal of Material Culture. [On line, 16 (2). Disponible en: https://journals.sagepub.com/doi/ $10.1177 / 1359183511401497$

Lazzari, M. (2012, septiembre). El pasado-presente como espacio social vivido: identidades y materialidades en Sudamérica y más allá (primera parte). Nuevo Mundo Mundos Nuevos. [On line]. Disponible en: http://journals.openedition.org/nuevomundo/64015

Lecoq, P. (1987). Caravanes de lamas, sel et échangesdans une communauté de Potosi, Bolivie. Bulletin de l'IFEA, XVI (3-4), 1-38.

Lema, V. y Pazzarelli, F. (2015, junio). Memoria fértil. Crianza de la historia en Huachichocana. Nuevo Mundo Mundos Nuevos. [On line]. Disponible en: https://journals.openedition.org/ nuevomundo/67976

Lorandi, A. M. y Boixadós, R. (1987-1988). Etnohistoria de los Valles Calchaquíes en los siglos XVI y XVII. Runa. [On line], 17-18. Disponible en: http://revistascientificas.filo.uba.ar/index.php/ runa/article/view/4326 
Martínez, B. (2012). Diablos, mito-praxis y experiencia histórica cajonista en los ingenios azucareros. Revista Brasileira Sociologia da Emocao [On line], 11 (32). Disponible en: http:// www.cchla.ufpb.br/rbse/RBSE\%2011.32.ago2012\%20completa\%20em\%20Word.pdf

Martínez, B. (2013). Imaginarios, interrelación y transformación social. El Cajón, entre la "modernidad" y el "proteccionismo". Estudios sobre las culturas contemporáneas. [On line], Época III Vol XIX (38). Disponible en: https://portal.ucol.mx/cuis/revistaculturas/articulos.htm? revista $=55$

Martínez, B. (2014a). Dios, Cristo y el Maligno: disputas cosmológicas y ciclos temporales en San Antonio del Cajón (Catamarca, Argentina). Estudios atacameños [On line], 49. Disponible en:https://scielo.conicyt.cl/scielo.php? script=sci_abstract\&pid=S0718-10432014000300010\&lng=p\&nrm=iso\&tlng=es

Martínez, B. (2014b). Cartografías en tránsito: mapas orales y memoria social en El Cajón (Catamarca, Argentina). Runa [On line], 35 (1). Disponible en: http:// revistascientificas.filo.uba.ar/index.php/runa/article/view/605

Martínez, B. (2015). Tiempo e interpretación en San Antonio (Catamarca, Argentina). Revista Polis [On line], 42. Disponible en: https://journals.openedition.org/polis/11400

Miller, D. (1998). Why some things matter. En D. Miller. (Ed.), Material cultures (pp. 3-21). Londres: University College London Press.

Miller, D. (2005). Materiality: an introduction. En D. Miller (Ed.), Materiality (pp. 1-50). Durham: Duke University Press.

Meskell, L. (2004). Object worlds in ancient Egypt: Material biographies Past and Present. Oxford: Berg Publishers.

Montenegro, M. (2014). Una experiencia de arqueología pública y colaboración intercultural en el sector septentrional de Argentina. Revista de Arqueología Pública. [On line], 10. Disponible en: https://doi.org/10.20396/rap.v8i2.8635637

Myers, F. (2005). Some properties of art and culture: ontologies of the image and economies of exchange. En D. Miller (Ed.), Materiality (pp. 88-117). Durham: Duke University Press.

Pazzarelli, F. y Lema, V. (2018). Paisajes, vidas y equivocaciones en los Andes Meridionales (Jujuy, Argentina). Chungara. [On line], 50 (2). Disponible en: http://www.chungara.cl/index.php/es/? option=com_content\&view=article\&id=228\&catid=14\&lang=es-ES

Rivet, M. C. y Tomasi, J. (2016). Casitas y casas mochas. Los antiguos y los abuelos en sus arquitecturas (Coranzulí y Susques, provincia de Jujuy, Argentina). En L. Bugallo y M. Vilca (Comps.), Wak'as, diablos y muertos. Alteridades significantes en el mundo andino (pp. 373-411). Jujuy: IFEA/EDIUNJU.

Rowlands, M. (2005). A Materialist Approach to Materiality. En D. Miller (Ed.). Materiality (pp. 72-87). Durham: Duke University Press

Rutledge, I. (1987). Cambio agrario e integración. El desarrollo del capitalismo en Jujuy: 1550-1960. Serie Antropología Social e Historia, 1. Jujuy: ECIRA-CISCO.

Sahlins, M. (1988). Islas de historia. Barcelona: Gedisa.

Sillar, B. (2013). The building and rebuilding of walls: Aspirations, commitments and tensions within an Andean community and the archaeological monument they inhabit. Journal of material culture [On line], 18 (1). Disponible en: https://journals.sagepub.com/doi/full/

$10.1177 / 1359183512473558$ 
Sturzenegger, O. (1981). En torno a los tapados. Entregas del Instituto Tilcara 12, 1-17.

Tacchi, J. (1998). Radio texture: between self and others. En D. Miller (Ed.), Material cultures (pp. 3-21). Londres: University College London Press.

Tilley, C. (1998). Metaphor and material culture. Oxford: Blackwell Publishers.

Wright, P. (2008). Ser en el sueño. Crónicas de historia y vida toba. Buenos Aires: Biblos.

Fuentes

Archivo Parroquial de El Cajón. Libro Diario de Fábrica (1924). San Antonio del Cajón.

\section{NOTES}

1. Esta investigación se llevó a cabo con los fondos provistos por el Proyecto $201 \mathrm{~N}^{\circ} 424 / 16$ otorgado por la Agencia Nacional de Promoción Científica y Tecnológica

La localidad San Antonio del Cajón se ubica en el valle homónimo, al norte de la provincia de Catamarca. Limita hacia el norte con la población de Ovejería y hacia el sur con Toro Yaco. En los próximos apartados se describirá la zona con mayor detalle. .

2. La señalada es una ceremonia en la que se propicia la reproducción del ganado sahumándolo, decorándolo con flores de lana, salpicándolo con bebidas. También se escogen un macho y una hembra jóvenes, se los casa y se espera que se multipliquen.

3. El tiempo de los indios refiere, en términos analíticos, a una discontinuidad temporal caracterizada por la presencia de seres presociales e indómitos, que murieron en un diluvio enviado por Cristo, quien se encolerizó ante su desconocimiento de las Sagradas Escrituras (Martínez, 2015).

4. Por ejemplo, Jofré et al. (2008) y Montenegro (2014), entre otros.

5. Quedará fuera de este trabajo el análisis de las valoraciones sobre los restos óseos humanos, o los objetos asociados con ellos (como por ejemplo los pucos y las urnas funerarias, cuya mención en este artículo se hará más adelante solo de modo ilustrativo). Por el momento. adelantaré que los restos humanos tienen un rol muy diferente al de los objetos, pues parecen condensar una agencia relevante y compleja, ligada al ciclo diario. Además, su articulación con el pasado los torna importantes aliados en acciones que las personas no pueden completar por sí mismas (v. gr. algunos rituales de adivinación). Sin embargo, el abordaje de estas cuestiones implicaría un estudio de las asociaciones con los ancestros y las formas concretas en que se desarrolla la sociabilidad material e inmaterial (Fontein, 2010), que merece un análisis específico, actualmente en desarrollo.

6. Podemos tomar como ejemplo de nuestro campo a la piedra del rayo, cuyo tamaño o color no resultaría de gran atractivo para un desconocedor de sus propiedades, pero que posee una gran densidad y relevancia en razón tanto de su escasez como de su utilidad en los procesos terapéuticos.

7. En la etiqueta cajonista, las preguntas directas son consideradas groseras. Por ello, la demanda de información suele depender de un largo derrotero circular que se extiende por horas o días.

8. Durante cada fase del trabajo de campo ellos fueron informados del contenido y alcance de las investigaciones. En algunos casos, solicitaron explícitamente que sus nombres fueran mencionados en las publicaciones. En otros, se escogió el anonimato.

9. Debido a las dificultades de acceso a los objetos industriales en razón a la distancia que separa San Antonio de Santa María, gran parte de ellos son utilizados hasta su virtual desintegración. Por ejemplo, una simple bolsa de nylon, de las que comúnmente son entregadas en los mercados, puede convertirse en un pequeño tesoro. Si se rompe, es reparada, reutilizándose una y otra vez, 
hasta su total destrucción. Así, un objeto como éste, de fácil acceso y descarte en la ciudad, en el contexto de El Cajón posee una extensa vida social (Appadurai, 1991).

10. Las dificultades de la aplicación del orden taxonómico derivado de la ciencia occidental para el análisis de estos tópicos han sido abordadas en otro sitio (Martínez, 2014b).

11. Es decir, formas en que, a viva voz, despliegan su imaginación cartográfica condensando nociones sobre la historia, la geografía, los mitos y las prácticas culturales.

12. Transitar este paisaje puede ser un acto individual. Sin embargo, en última instancia no deja de ser una práctica social, pues los movimientos de la gente dentro del poblado y el área que lo circunda son presenciados, observados e identificados por los demás, aun a largas distancias.

13. Estas actividades fueron continuadas por el cura Vázquez, figura central en el imaginario histórico local, y los diversos sacerdotes agustinos que desde 1969 arribaron a la zona. Paulatinamente, en el poblado se gestó una fuerte identidad católica, que en la actualidad implica una férrea impugnación a las alternativas religiosas no católicas.

14. Se ha sugerido que las antiguas paredes pueden actuar protegiendo a los sembrados contra el viento y las bajas temperaturas, colaboran en el proceso de maduración de los cultivos y ayudan a retener la humedad (Sillar, 2013).

15. Sintéticamente, señalaré que en San Antonio el ciclo diario se organiza en cuatro secciones articuladas por fronteras parcialmente solapadas. La hora de la oración es el período que abarca aproximadamente entre el atardecer y la medianoche. En este lapso los muertos y los seres nocturnos como el demonio y sus aliados pueden vagar por el poblado. La medianoche es el momento propicio para las curaciones (en especial aquellas en las que intervienen las personas a favor de los poderes de Cristo, como el caso de la enfermedad del susto que implica la pérdida temporal del alma). Por su parte, la hora del canto del gallo marca el amanecer, en el que Dios y Cristo retoman fuerzas. Finalmente, el mediodía es cuando Dios y Cristo poseen el pleno empleo de su poderío, y por tanto las personas, sus aliadas, pueden ejercer sus actividades con mayor soltura. Los desequilibrios de fuerzas que ocurren en el ciclo diario se encuentran estrechamente enlazados con los que acontecen en el ciclo anual, como mostré en otro sitio (Martínez, 2014a).

16. Tapado es el término nativo que se utiliza en buena parte del noroeste argentino para referirse a tesoros ocultos bajo la tierra (cfr. Sturzenegger,1981).

17. La ligazón entre agosto y la emergencia de los tapados también ha sido estudiada por Gerardo Fernández Juárez (1996).

18. Ello ocurre especialmente el 24 de agosto, día de San Bartolo. Las relaciones entre este santo, los tapados y la plata fueron analizados en Martínez (2012).

19. Por supuesto, no me refiero a la totalidad del mes ni a la totalidad de las noches, pues la aparición de estas manifestaciones fluctúa.

20. "Ellos han encontrado esas muyunas en los antigales y los usan para poner en el huso que usan para hacer el hilo. Lo ponen en la parte inferior para que le de equilibrio al huso y al mismo tiempo sujetan el hilo que van haciendo. Ellos lo hacen girar al huso y esa muyuna le ayuda a que gire el huso. Debe tener ocho cm de diámetro". (Walter Albarracín, Santa María, 2020).

21. Estas consisten en piedras con una concavidad profunda, de aproximadamente un metro de largo, que en la perspectiva nativa era utilizada en el tiempo de los indios para facilitar el trabajo de parto.

22. Las urnas funerarias (ollas funerarias, funerarias $\mathrm{u}$ ollitas en la narrativa cajonista), y los pucos han sido estudiados de manera exhaustiva en Ambrosetti (1889-1890).

23. Excepcionalmente es posible encontrar algunas ollas funerarias en los hogares. Son utilizadas como contenedores de elementos (por ejemplo, documentos), o bien como objeto ornamental. En su andar cotidiano las personas suelen hallar pucos bastante fragmentados, de modo que finalmente resultan trozos que pululan dispersos por la casa. Sin embargo, desde la perspectiva local se hallan asociados con los muertos, y su presencia no es inerte. Como mencioné, me ocupo de estos objetos en otro artículo actualmente en elaboración. 
24. En la narrativa nativa no resultan relevantes puesto que "no se sabe bien para qué lo usaba la gente de antes, debe ser para ayudar a la mujer a tener al bebé, por la forma bien marcada, pero no se sabe" (Walter Albarracín, Santa María, 2020).

25. Churo/a es una palabra nativa utilizada corrientemente para designar a una persona laboriosa y tenaz. Ocasionalmente puede emplearse, como esta vez, para describir las cualidades de los objetos.

26. También recibe el nombre de batán en algunas poblaciones de Perú y Bolivia.

27. Para Christopher Tilley (1998), esta noción refiere al modo en que un dominio conceptual (por ejemplo, el imaginario de los turistas), en la praxis se plasma en un dominio más concreto (en nuestro caso, la hostería).

28. La historia de la constitución de la arqueología como disciplina también ilustra el modo en que, en diversos momentos, el "otro" indígena fue confinado al pasado (Angelo, 2005; Fabian, 1983; Conforti y Endere, 2012).

29. Andrew Canessa (2012) destaca que la insistencia en que los indígenas muestren una continuidad cultural es en definitiva otro modo de negar su pasado, pues este mecanismo contribuye a ocultar los modos creativos mediante los que la gente creó por siglos su propio devenir. Al respecto también puede leerse el análisis de James Clifford (1995) sobre la identidad entre los mashpee.

\section{ABSTRACTS}

This work addresses, from an ethnographic perspective, the ways in which the people in San Antonio del Cajón (Catamarca, Argentina) socialize with objects and sites from the past. Faced with positions that stress the political appropriation of objects and sites in contexts of ethnic claims such as the Cajonista, this text studies the material and immaterial aspects, as well as the posible practical uses which culminate in a contemporary reuse. Thereby, it highlights the way in which some cultural processes run parallel to others, such as the political demands, without being overridden and articulately overlapping.

Este artículo aborda, desde una perspectiva etnográfica, los modos en que la gente de San Antonio del Cajón (Catamarca, Argentina) socializa con los objetos y sitios del pasado. Frente a posturas que ponen el acento en la apropiación política de los objetos y sitios en contextos de reivindicación étnica como el cajonista, en este texto se estudian los aspectos materiales e inmateriales, así como los posibles usos prácticos, que culminan en una reutilización contemporánea. De este modo, resalta el modo en que algunos procesos culturales corren en paralelo a otros, como las reivindicaciones políticas, sin anularse y superponiéndose articuladamente.

INDEX

Keywords: materiality, inmateriality, past, ethnic claims

Palabras claves: materialidad, inmaterialidad, pasado, reivindicación étnica 


\section{AUTHOR}

\section{BÁRBARA BETSABÉ MARTÍNEZ}

Instituto de Ciencias Antropológicas, Facultad de Filosofía y Letras, Universidad de Buenos Aires. Consejo Nacional de Investigaciones Científicas y Técnicas. Argentina.

Correo electrónico: bmartinez@filo.uba.ar 